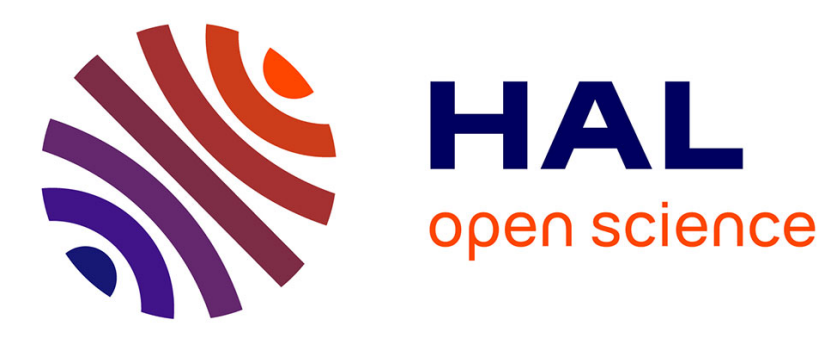

\title{
Survival impact of primary site surgery on metastatic breast cancer patients at diagnosis
}

\author{
H. Desille-Gbaguidi, S. Avigdor, G. Body, Lobna Ouldamer
}

\section{To cite this version:}

H. Desille-Gbaguidi, S. Avigdor, G. Body, Lobna Ouldamer. Survival impact of primary site surgery on metastatic breast cancer patients at diagnosis. Journal of Gynecology Obstetrics and Human Reproduction, 2019, 48, pp.171 - 177. 10.1016/j.jogoh.2018.10.014 . hal-03486578

\section{HAL Id: hal-03486578 https://hal.science/hal-03486578}

Submitted on 20 Dec 2021

HAL is a multi-disciplinary open access archive for the deposit and dissemination of scientific research documents, whether they are published or not. The documents may come from teaching and research institutions in France or abroad, or from public or private research centers.
L'archive ouverte pluridisciplinaire HAL, est destinée au dépôt et à la diffusion de documents scientifiques de niveau recherche, publiés ou non, émanant des établissements d'enseignement et de recherche français ou étrangers, des laboratoires publics ou privés.

\section{다)(1) $(5$}

Distributed under a Creative Commons Attribution - NonCommerciall 4.0 International 


\section{Survival Impact of primary site surgery on metastatic breast cancer patients at diagnosis}

H. Desille-Gbaguidi ${ }^{1,2}$, S. Avigdor ${ }^{4}$, G. Body ${ }^{1,2}$, L.Ouldamer ${ }^{1,2,3}$

${ }^{1}$ Department of Gynecology. Centre Hospitalier Régional Universitaire de Tours. Hôpital Bretonneau. 2 boulevard Tonnelé. 37044 TOURS. France.

${ }^{2}$ François-Rabelais University, Tours. France.

${ }^{3}$ INSERM unit 1069, Tours. France.

${ }^{4}$ Department of Gynecology and Obstetric, Madeleine Hospital, Orléans, France

primary site surgery and metastatic breast cancer 


\begin{abstract}

\section{Background:}

Stage IV breast cancer was considered to be an incurable disease. Primary site surgery used to be reserved to control local complications. In the present study, we compared the survival of women who received therapeutic breast surgery for stage IV breast cancer at initial diagnosis to the survival of those who did not.
\end{abstract}

\title{
Methods:
}

Two French hospitals databases were retrospectively screened from 2005 to 2012. We identified all women with metastatic breast cancer at diagnosis. Patients' data were obtained by a review of their medical history. Data were analysed according the four breast cancer subtypes (luminal A, luminal B, her 2 and triple negative).

\section{Results:}

One hundred thirty nine women were included, of whom 69 had primary site surgery. TNM stage and phenotypes of breast cancer were comparable in the two groups but operated women were younger than women who did not $(\mathrm{p}<0.0001)$. Average follow-up was $31 \pm 23.3$ months [1-97]. Through logistic regression, we observed that tumor resection decreased death hazard ratio vs no surgery: HR $0.33,95 \%$ CI [0.16-0.66] p=0.001. In the surgery group, there was no survival difference if women received chemotherapy $(\mathrm{p}=0.23)$. There were more patients with only one metastatic site in the surgery group $(\mathrm{p}=0.002)$ and they had been more treated with systemic therapy. When we compared tumor phenotypes individually, surgery increased survival on luminal A breast cancer patients $(\mathrm{p}<.0001)$.

\section{Conclusion:}

Women with luminal A breast cancer and synchronous metastasis seemed to benefit from surgery. The development of a national reporting system or registers for outcomes would facilitate the investigation of the disease across a multitude of aspects of stage IV breast cancer.

Key words: breast cancer; breast cancer phenotype; metastases; survival 


\section{Introduction:}

Breast cancer is the first cancer-affecting women in developed countries. Among the women affected, 3-10\% has distant metastases at initial presentation. The survival of breast cancer patients presenting with metastases at diagnosis has improved ${ }^{1}$. It is still considered as an incurable disease without any consensual standard treatment. Primary site surgery has been reserved for symptomatic wound complications to prevent or control local complications. It is generally admitted in this case that tumor excision does not increase survival. Palliative systemic therapy (hormonal, chemotherapy or targeted therapy) is started according to age, comorbidities and symptoms. Therapeutic strategy is then adapted to disease response.

Khan et $\mathrm{al}^{2}$ were the first who asked: "Does aggressive local therapy improve survival in metastatic breast cancer?". They retrospectively included 16.023 patients and concluded that women treated with primary cancer surgical resection with free margins had superior survival with a hazard ratio of 0.61 (95\%CI 0.58-0.65). The available literature regarding this subject comprises retrospective observational studies. In 2006, two studies ${ }^{3,4}$ with respectively 317 and 224 patients showed contradictory results. In 2007, Fields et $\mathrm{al}^{5}$ reported the data of 409 patients from 1988 to 2003 . They concluded that patients who underwent surgical resection had longer median survival when compared to patients who did not undergo surgery (HR 0.53, 95\%CI [0.42-0.67]). The largest study was reported by Gnerlich et $\mathrm{al}^{6}(16.023$ patients), Their results showed that extirpation of the primary breast cancer tumor in patients with stage IV disease was associated with a marked reduction in risk of dying (HR 0.63, 95\% CI [0.60-0.66]) but location of metastatic sites and use of chemotherapy or hormonal therapy were not recorded in the database. In 2008, Shien et $\mathrm{al}^{7}$ in a study including 344 patients managed from 1962 to 2007, showed an increase of survival in the surgery group when patients were young (under 50 years old). In 2009 , three studies ${ }^{8,9,10}$ did not find any positive effect of surgery on overall survival in patients with primary metastatic breast cancer whereas Ruiterkamp $^{11}$ et al found in their cohort (728 patients managed from 1993 to 2004) that surgery appeared to be an independent prognosis factor.

Nowadays, in the era of molecular signature, we know that there are several phenotypes of breast cancer. Their prognoses are different. The treatment proposed must be

adapted to each subtype. Neuman et $\mathrm{al}^{12}$ in 2010 was the first who searched for a relationship between surgery in stage IV breast cancer patients and tumor molecular subtype. 
In our study, we aimed to assess differences in characteristics and outcomes of patients who received therapeutic breast surgery for stage IV breast cancer at initial diagnosis (surgery group) compared to patients who did not (no surgery group). The major issue of our study was to target which patient could take advantage of primary site surgery.

\section{Material and methods:}

- Study population:

In our descriptive study, two French hospitals databases (university teaching hospital of Tours and regional hospital of Orléans) were retrospectively screened to identify all women with metastatic breast cancer at diagnosis. Women were included from January 1st, 2005 to December 31th, 2012. Patients' data were obtained by a review of their medical history. We chose not to select patients diagnosed before 2005 to have a uniform cohort. Indeed, all patients could have her2 status testing and if needed, benefit from treatment with targeted therapy (Trastuzumab). Patients with personal history of breast cancer or another primary cancer were not included because of the impossibility to affirm which primary tumor led to the metastatic disease.

- Data collected:

Medical records were reviewed for menopausal status, body mass index (BMI) and date of diagnosis. Tumor characteristics were also recorded. Clinical stage was established following the TNM stage system ${ }^{13}(\mathrm{~T} 1<2 \mathrm{~cm}, \mathrm{~T} 22-5 \mathrm{~cm}, \mathrm{~T} 3>5 \mathrm{~cm}$, T4 inflammatory or skin/thoracic wall involvement; N1 axillary lymph node N2 fixed axillary lymph node N3 supraclavicular or controlateral node involvement). We recorded also if there were several tumors in the same breast or on the two sides. Thanks to hormonal receptor presence and her2 status, we grouped tumors in subtypes ${ }^{14-17}$. Four phenotypes were determined: luminal A (hormonal receptor positive, her status negative), luminal B (oestrogene or progestogen receptor positive, her2 status positive), her2 overexpression (hormonal receptor negative and her 2 status positive) and triple negative (hormonal receptor and her2 status negative). In case of herceptest ++, a FISH amplification technique was performed.

Metastases were classified in three different major sites: bone metastases, visceral metastases and brain metastases. Visceral metastases included lung, pleura, mediastinal and 
liver metastases. We choose to separate the brain metastases because of their own bad prognosis. Treatments received were compared: primary cancer surgery, chemotherapy (before and/or after surgery), hormonal therapy, Trastuzumab and radiation to primary site. Surgery was classified in time of surgery (before systemic therapy if metastatic was unknown), conservative or not, free or positive margins and axillary lymph node exploration. Follow up was performed according to consultations or hospitalisations. In the cases when we did not have any recent data, we called general practitioner.

- Statistical analysis :

Data were analyzed using R2.13.1 (http://www.cran.r-project.org/). For numerical data, results are reported as mean and median values \pm standard deviation (SD). The Fischer exact and $\chi^{2}$ chi-square tests were used to compare categorical values. Student tests were used for continuous values. We considered $\mathrm{p}<0.05$ to be statistically significant. For the survival analysis, data on surviving patients without disease recurrence or progression were censored on the date of their last follow-up examination. Survival curves were generated (in months) using the method of kaplan-meier, based on the interval from the date of diagnosis to the date of last contact or death from any cause. The log-rank test was used to compare differences between survival curves. 


\section{Results:}

- Population Characteristics (table 1)

139 patients with stage IV breast cancer at initial presentation were included in our study, of them, 70 were recorded in the university hospital center of Tours and 69 in the Orléans Hospital. This amounts to $2.6 \%$ of breast cancers diagnosed in the study period in these hospitals. The study population characteristics are provided in Table 1.

In our cohort, 69 patients $(49.6 \%)$ had primary site surgery, of whom 22 (31.9\%) had unknown metastatic disease at the time of surgery. They were found to have stage IV breast cancer by imaging procedures performed in the post-operative period.

$\underline{\text { Table } 1 \text { Population characteristics }}$

\begin{tabular}{|c|c|c|c|}
\hline & $\begin{array}{c}\text { All patients } \\
(\mathrm{n}=139)\end{array}$ & $\begin{array}{c}\text { With surgery } \\
(n=69)\end{array}$ & $\begin{array}{c}\text { Without surgery } \\
(n=70)\end{array}$ \\
\hline Mean age (year \pm SD,range) & $62.7 \pm 15.4[25-94]$ & $56 \pm 15.4[25-93]$ & $67.9 \pm 13.7[41-94]$ \\
\hline$<40$ years & $10(7.1 \%)$ & $10(14.5 \%)$ & 0 \\
\hline$\geq 75$ years & $37(26.6 \%)$ & $12(17.4 \%)$ & $25(35.7 \%)$ \\
\hline Mean body mass index $\left(\mathrm{kg} / \mathrm{m}^{2}\right)$ & $26.9 \pm 5.9[16-56.2]$ & $26.5 \pm 4.8[19.6-40.2]$ & $27.4 \pm 7.2[16-56.2]$ \\
\hline During pregnancy & 1 & 1 & 0 \\
\hline \multicolumn{4}{|l|}{ Menopausal status } \\
\hline Postmenopausal & $105(75.5 \%)$ & $44(63.8 \%)$ & $61(87.1 \%)$ \\
\hline Premenopausal & $34(24.4 \%)$ & $25(36.2 \%)$ & $9(12.8 \%)$ \\
\hline
\end{tabular}

Operated patients were younger $(\mathrm{p}<.0001)$ than patients of the no surgery group but had comparable BMI $(\mathrm{p}=0.38)$. There were more patients who were under 40 years old in the surgery group $(\mathrm{p}=.0006)$, and more patients who were over 75 years old in the no surgery group ( $\mathrm{p}=.003)$. There were more postmenopausal patients in the no surgery group $(\mathrm{p}=.001)$.

- Disease characteristics (table 2)

The histological types were invasive ductal carcinoma, invasive lobular carcinoma, mixed or poorly differenciated. Their repartition were equivalent between the two groups $(\mathrm{p}=0.13)$. There were as many inflammatory tumors $(\mathrm{p}=0.8)$ and bilateral tumors $(\mathrm{p}=0.7)$ in the surgery group as in the non surgery group. Concerning the tumor's size, clinical $(p=0.72)$ 
and radiological mensurations $(\mathrm{p}=0.48)$ were comparable between the two groups. Oestrogen receptor expression $(\mathrm{p}=0.33)$, her 2 neu status $(\mathrm{p}=0.64)$ and cancer phenotype type $(\mathrm{p}=0.22)$ were also comparable in the two groups. There were more multifocal tumor in the surgery group $(\mathrm{p}=.002)$ and more progestogen receptor expression $(\mathrm{p}<.0001)$ as compared to there were in non operated on patients.

Table 2: Cancer characteristics

\begin{tabular}{|c|c|c|c|}
\hline & $\begin{array}{l}\text { All patients } \\
(n=139)\end{array}$ & $\begin{array}{l}\text { Patients with surgery } \\
\qquad(\mathrm{n}=69)\end{array}$ & $\begin{array}{c}\text { Without surgery } \\
(n=70)\end{array}$ \\
\hline Multifocal & $26(18.7 \%)$ & $20(28.9 \%)$ & $6(8.6 \%)$ \\
\hline Inflammatory & $35(25.2 \%)$ & $18(26.1 \%)$ & $17(24.3 \%)$ \\
\hline Bilateral breast cancer & $6(4.3 \%)$ & $2(2.9 \%)$ & $4(5.7 \%)$ \\
\hline Clinical size (mm) & $73.1 \pm 50.7[0-300]$ & $74.5 \pm 44.1[0-180]$ & $71.4 \pm 56.4[0-300]$ \\
\hline Radiological size (mm) & $60.6 \pm 47.7[0-300]$ & $57.8 \pm 38.3[8-180]$ & $63.6 \pm 56.3[0-300]$ \\
\hline \multicolumn{4}{|l|}{ T status } \\
\hline T0 & $2(1,4 \%)$ & $0(0 \%)$ & $2(2.8 \%)$ \\
\hline T1 & $7(5 \%)$ & $5(7.2 \%)$ & $2(2.8 \%)$ \\
\hline $\mathbf{T} 2$ & $43(30,9 \%)$ & $22(31.8 \%)$ & $21(30 \%)$ \\
\hline T3 & $23(16,5 \%)$ & $13(18.8 \%)$ & $10(14.3 \%)$ \\
\hline T4 & $64(46 \%)$ & $29(42 \%)$ & $35(50 \%)$ \\
\hline \multicolumn{4}{|l|}{ N status } \\
\hline $\begin{array}{l}\text { No } \\
\text { pNo }\end{array}$ & $48(34.5 \%)$ & $\begin{array}{c}35(50.7 \%) \\
5(19.2 \%)\end{array}$ & $13(18.6 \%)$ \\
\hline N1 & $53(38.1 \%)$ & $29(29 \%)$ & $24(34.3 \%)$ \\
\hline $\mathbf{N 2}$ & $20(14.4 \%)$ & $2(2.9 \%)$ & $18(25.7 \%)$ \\
\hline N3 & $7(5 \%)$ & $2(2.9 \%)$ & $5(7.1 \%)$ \\
\hline Invasive ductal carcinoma & $86(61.9 \%)$ & $47(68.1 \%)$ & $39(55.7 \%)$ \\
\hline Invasive lobular carcinoma & $18(12.9 \%)$ & $9(13 \%)$ & $9(12.8 \%)$ \\
\hline Mixed & $19(13.7 \%)$ & $6(8.7 \%)$ & $13(18.6 \%)$ \\
\hline Poorly differenciated & $16(11.5 \%)$ & $7(7.2 \%)$ & $9(12.8 \%)$ \\
\hline ER status positive & $108(77.7 \%)$ & $56(81.1 \%)$ & $52(74.3 \%)$ \\
\hline PR status positive & $91(65.5 \%)$ & $56(81.1 \%)$ & $35(50 \%)$ \\
\hline Her2neu status positive & $28(20.1 \%)$ & $15(21.7 \%)$ & $13(18.6 \%)$ \\
\hline \multicolumn{4}{|l|}{ Phenotype } \\
\hline Luminal A & $94(67.6 \%)$ & $50(72.4 \%)$ & $44(62.8 \%)$ \\
\hline Luminal B & $17(12.2 \%)$ & $7(10.1 \%)$ & $10(14.3 \%)$ \\
\hline Triple negative & $17(12.2 \%)$ & $4(5.8 \%)$ & $13(18.6 \%)$ \\
\hline Her & $11(7.9 \%)$ & $8(11.6 \%)$ & $3(4.3 \%)$ \\
\hline
\end{tabular}

Number of sites 


\begin{tabular}{lccc}
\multicolumn{1}{c}{$\mathbf{1}$} & $78(56.1 \%)$ & $48(69.5 \%)$ & $30(42.8 \%)$ \\
$\mathbf{2}$ & $43(30.9 \%)$ & $17(24.3 \%)$ & $26(37.1 \%)$ \\
$\mathbf{3}$ & $16(11.5 \%)$ & $4(5.7 \%)$ & $12(17.1 \%)$ \\
\multicolumn{1}{|c}{} & $1(0.7 \%)$ & 0 & $1(1.4 \%)$ \\
Bone metastasis & $1(0.7 \%)$ & 0 & $1(1.4 \%)$ \\
Visceral metastasis & $99(71.2 \%)$ & $49(51.1 \%)$ & $50(71.4 \%)$ \\
Brain metastasis & $80(57.6 \%)$ & $30(43.5 \%)$ & $50(71.4 \%)$ \\
Chemotherapy & $8(5.8 \%)$ & $3(4.3 \%)$ & $5(7.1 \%)$ \\
Hormonal therapy & $91(65.5 \%)$ & $53(76.8 \%)$ & $38(54.2 \%)$ \\
Trastuzumab & $97(69.8 \%)$ & $56(81.1 \%)$ & $41(58.6 \%)$ \\
Radiation to primary & $19(13.7 \%)$ & $10(14.5 \%)$ & $9(12.8 \%)$ \\
\hline
\end{tabular}

Metastases characteristics are described in table 2. For overall population, 54 (38.8\%) patients had only bone metastasis, $23(16.5 \%)$ only visceral metastasis and one patient $(0.7 \%)$ had only one cerebral metastasis. In the surgery group, 34 patients $(49.3 \%)$ had only bone metastasis, $13(18.8 \%)$ only visceral metastasis and one patient $(1.4 \%)$ only one cerebral metastasis. There were more patients with one metastatic site in the surgery group $(\mathrm{p}=0.002)$.

\section{- Treatments}

Primary site surgery concerned 69 patients (49.6\%) 22 of whom (29\%) had breast conservative surgery. The margins were positive for 7 patients $(31.8 \%)$. Fifty five women (79.7\%) had an associated axillary surgery (axillary lymph node dissection total, partial lymph node resection or sentinel lymph node biopsy) with a mean number of lymph nodes resected of $11 \pm 6$ [1-25] and a mean number of positive axillary lymph nodes of 4 5 [0-20]. Systemic treatments are described in Table 2.

In the surgery group, $26 \%(n=18)$ had chemotherapy before surgery, 33\% $(n=23)$ after surgery and $17 \%(\mathrm{n}=12)$ had both. For Luminal A patients, women who had surgery to primary received more chemotherapy ( $70 \%$ for the surgery group vs $48 \%$ for the non surgery group) and more hormonotherapy than non operated patients ( $\mathrm{p}=0.03, \mathrm{p}=0.01$ respectively) but radiation to primary was equivalent $\mathrm{p}=0.45$.

\section{- Survival}

Overall survival was $46.1 \%$ for all patients. Average follow-up was $31 \pm 23.3$ months [1-97] for all patients, $40.7 \pm 22.6$ months [2-97] for the surgery group and $21.3 \pm 19.8$ months 
[0-97] for the non surgery group. 75 patients (53.9\%) died among whom $28(37.3 \%)$ had primary site surgery. Overall survival was $59.4 \%$ in the surgery group versus $32.8 \%$ for the no surgery group $(\mathrm{p}<.0001)$. The figure 1 shows the Kaplan-Meier survival curves of all patients comparing surgery to no surgery. Through logistic regression, we observed that tumor resection decreases death hazard ratio vs no surgery: HR $0.33,95 \%$ CI $[0.16-0.66] \mathrm{p}=.001$.

For overall population, survival was statistically different depending on tumor phenotype (figure 2) $\mathrm{p}<.0001$. The mortality rate was $52 \%$ for luminal A phenotype (49/94), $35 \%$ for luminal B phenotype (6/17), 55\% for her2 phenotype (6/11) and $82 \%$ for triple negative phenotype (14/17).

In the surgery group, survival difference did not statistically vary with age for patients (under 40 years old $\mathrm{p}=0.76$ or over 75 years old $\mathrm{p}=0.72)$, menopausal status $(\mathrm{p}=0.12)$, cancer characteristics ( $\mathrm{T}$ stage $\mathrm{p}=0.3, \mathrm{~N}$ stage $\mathrm{p}=0.32$, inflammatory $\mathrm{p}=0.68$, multifocality $\mathrm{p}=0.84$, eostrogen receptor $\mathrm{p}=0.08$, progestogen $\mathrm{p}=0.24$, her2neu status $\mathrm{p}=0.16$, lymphovascular invasion $\mathrm{p}=0.44$ or tumor phenotype $\mathrm{p}=0,22$ ). Mortality rate was $36 \%$ for luminal A subtype (18/50), 28,5\% for luminal B subtype (2/7), $75 \%$ for her2 subtype (6/8) and 50\% for triple negative subtype $(2 / 4)$.

Concerning the surgical procedure, survival did not depend on breast conservative surgery or mastectomy $(\mathrm{p}=0.64)$, free margins $(\mathrm{p}=0.43)$, axillary lymph node resection $(p=0.23)$. There was no survival difference if chemotherapy was before surgery $(p=0.27)$ or chemotherapy before or after surgery $(\mathrm{p}=0.23)$.

When we compared tumor phenotypes individually (figure $3 \mathrm{a}-\mathrm{b}$ ), survival was statistically different between the two groups for luminal A breast cancer patients $\mathrm{p}<.0001$ (18 deaths for 50 patients in the surgery group and 33 deaths for 44 patients in the no surgery group) and for triple negative breast cancer patients $\mathrm{p}=.01$ ( 2 deaths for 4 patients in the surgery group and 12 death for 13 patients). For other phenotypes (figure $3 \mathrm{c}$-d) there was no statistical difference between surgery vs no surgery (luminal B: 2 deaths for 7 patients in the surgery group and 4 deaths for 10 patients in the no surgery group $p=0.42$; her2: 6 deaths for 8 patients in the surgery group and 0 death for 3 patients in the no surgery group $p=0.15$ ).

In the surgery group, we observed that through logistic regression, patients treated with radiotherapy to primary site decreased their death rate: $\mathrm{HR}=0.14,95 \% \mathrm{CI}[0.03-0.54]$ 
$\mathrm{p}=0.007$. There was a statistical survival difference depending on metastatic site number $\mathrm{p}=0.005$ (figure 4 ). The mortality rate of patients who had one metastatic site was $35 \%$ versus $41 \%$ for patients who had two metastatic sites. All patients with three or more sites of metastases died during the follow up. A patient with three metastatic sites vs only one site has a death hazard ratio (HR) estimated at 2,3,95\% CI[1.1-5.8]p=0.05. Survival did not vary with bone or visceral site $(\mathrm{p}=0.67$ vs $\mathrm{p}=0,52)$ but varied with cerebral site $\mathrm{p}<0.0001$ (25 deaths/66 patients without cerebral site vs 3 deaths/3 patients with cerebral site). 


\section{Discussion:}

We observed that for breast cancer patients with stage IV at initial diagnosis, tumor resection increases survival compared to no surgery: HR 0.33 [0.16-0.66] $\mathrm{p}=.001$. This is concordant with the systematic review of literature by Ruiterkamp et al ${ }^{18}$ who concluded that "surgery of the primary tumor appeared to be an independent factor for an improved survival" with a pool hazard ratio for overall mortality at 0.65 (95\% CI [0,59-0,72]). In seven years we have diagnosed 139 breast cancers with synchronous metastasis which represents $2.6 \%$ of the breast cancers identified and is comparable with literature $\left(3-10 \%{ }^{19}\right)$. In our overall population, we had more patients with luminal A subtype. This is indeed the most frequently subtype described and the one with a better prognosis ${ }^{20-21}$. As we already know ${ }^{22}$, patients with triple negative subtype and patients with three or more metastatic sites have had the worst prognosis.

On one side, many studies, including two databases, have found an increase in survival by performing surgery on metastatic breast cancer patients. ${ }^{23-25}$

A meta-analysis showed also a gain in survival at three years for patients who underwent surgery with an HR=2,32, IC95\%=[2,08; 2,6], p<0,01. (17) However, in this study patients operated on differ from patients who did not benefit from surgery concerning tumor size, number of metastasis and comorbidities. ${ }^{26}$

When we compared phenotypes individually, surgery increases survival for luminal A breast cancer patients $\mathrm{p}<.0001$ and for triple negative breast cancer patients $\mathrm{p}=.01$. There was no survival difference between surgery and non surgery groups for all patients with her2 tumors whatever their hormonal status. In the Cancer journal, Neuman and $\mathrm{al}^{12}$ in their study from 2000 to 2004 concluded that no survival benefit was observed in patients with triple negative disease $(\mathrm{p}<.001)$. Their patient number was 186 and they had 35 triple negative breast cancer patients.

Concerning the surgical procedure, survival does not depend on the type of surgery (conservative surgery or mastectomy). Like Ruiterkamp et $\mathrm{al}^{18}$ in their review of the literature, we did not find a significant contribution of nodal dissection to the prognosis. For lymph node surgical resection, there are neither consensual standard nor homogeneous results in literature. This is also the case for free margins. Two studies ${ }^{2,27}$ demonstrated that when the resection 
margins were tumor free, survival was increased but we observed, like Rapiti et $\mathrm{al}^{3}$ did, no difference.

In our study, we notice that surgery was more proposed in the university centre. So as recommendations are relatively hazy, treatment depends on work team in each centre. In France, we search systematically secondary localisations from T3 or T4. As there is metastatic disease with $\mathrm{T} 1$ or $\mathrm{T} 2$ without symptoms, there are patients in the surgery group who were operated on before the diagnosis of stage IV disease. According to Pedez-Fidalgo ${ }^{28}$ et al, carrying out surgery before or after systemic therapy does not affect survival $(p=0.996)$.

Retrospectively, we saw that patients in the group with surgery resection of primary tumor were younger. All patients under 40 years old were operated on. So there were more non menopausal patients in this group. This fact can be explained because young patients have a low anesthesia risk. Moreover their life expectancy is longer and they are exposed to local complication or local recidive.

Our two groups differed in age and metastatic number of sites. This selection bias was due to retrospective observation. Most studies in literature were retrospective. Thanks to his stratified analysis, Rapiti and $\mathrm{al}^{3}$ found that survival increases only in the bone metastasis group. For Fields there is an advantage if patients have only bone metastasis and if margins are free. Shien et $\mathrm{al}^{7}$ and Rashan et $\mathrm{al}^{29}$ demonstrate that younger patients had an increased survival. In our study, the low number of luminal B, her 2 and triple negative subtypes does not allow us to extrapolate our results for these ones. We observed more chemotherapy treatments in the surgery group and more particularly in the luminal A subtype. We cannot exclude a confusion bias. Cady et $\mathrm{al}^{8}$ in their matched pair analysis suggest that bias could be responsible for the impression of survival increase but their charts seems to show the contrary $^{18}$. In the light of literature, surgery seems unavoidable for young patients and complete responses after neo-adjuvant treatments.

In 2004, Bernard and $\mathrm{al}^{30}$ affirm that her2-overexpressing breast cancer could well be a distinct disease entity requiring a separate approach in terms of treatment. Our study is the first who included an homogeneous population since we started using trastuzumab treatment 
in 2004. We are among the first ones to evaluate surgery benefit separating the different subtypes of breast cancer with synchronous metastasis.

More recently, Tosello et al, published a review including two trials enrolling 624 women, they concluded that it is uncertain whether breast surgery improves overall survival as the quality of the evidence has been assessed as very low (HR 0.83 , 95\% CI 0.53 to 1.31). Breast surgery may improve local progression-free survival (HR $0.22,95 \%$ CI 0.08 to 0.57; while it probably worsened distant progression-free survival (HR 1.42, $95 \%$ CI 1.08 to 1.86). ${ }^{31}$

New technologies such as molecular signature and approximate classification in subtype by hormonal and her 2 receptors could allow us to adapt the standard of care for breast cancer with synchronous metastasis to the own development of each cancer and operate on only patients who could benefit from it.

In our study, patients with luminal A breast cancer phenotypes and synchronous metastasis seem to benefit from surgery. For these patients, tumor resection could not only prevent them from having local complications but also increase their survival.

There are still concerns about primary site surgery benefits for patients with stage IV breast cancer due to the influence of case selection on reported outcomes. Because of the multitude of stage IV breast cancer aspects, we need larger scale studies. The development of a national reporting system or registers for outcomes would facilitate the investigation of this disease. 


\section{References:}

1. Andre F, Slimane K, Bachelot T, Dunant A, Namer M, Barrelier A, Kabbaj O, Spano JP, Marsiglia H, Rouzier R, Delaloge S, Spielmann M. Breast cancer with synchronous metastases: trends in survival during a 14-year period. J Clin Oncol. 2004 Aug 15;22(16):3302-8

2. Khan SA, Stewart AK, Morrow M. Does aggressive local therapy improve survival in metastatic breast cancer? Surgery $2002 ; 132: 620-6$

3. Rapiti E, Verkooijen HM, Vlastos G, Fioretta G, Neyroud-Caspar I, Sappino AP, Chappuis PO, Bouchardy C. Complete excision of primary breast tumor improves survival of patients with metastatic breast cancer at diagnosis. J Clin Oncol 2006; 24:2743-2749

4. Babiera, GV, Rao, Roshni, Feng L, Meric-Bernstam F, Kuerer HM, Singletary SE, Hunt KK, Ross MI, Gwyn KM, Feig BW, Ames FC, Hortobagyi GN. Effects of primary tumor extirpation in breast cancer patients who present with stage IV disease and an intact primary tumor. Annals of surgical oncology 2006;13(6):776-782

5. Fields RC, Jeffe DB, Trinkaus, K, Zhang Q, Arthur C, Aft R, Dietz, JR, Eberlein T, Gillanders WE, Margenthaler JA. Surgical resection of the primary tumor associated with increased long-term survival in patients with stage IV breast cancer after controlling for site of metastasis. Annals of surgical oncology 2007;14(12):3345-3351

6. Gnerlich J, Jeffe DB, Deshpande AD, Beerts C, Zander C, Margenthaler JA. Surgical removel of the primary tumor increases overall survival in patients with metastatic breast cancer: analysis of the 1988-2003 SEER Data. Annals of surgical oncology 2007;14(8):2187-2194

7. Shien T, Kinoshita T, Shimizu C, Hojo T, Taira Naruto, Doihara H, Akashi-Tanaka S.Primary tumor resection improves the survival of younger patients with metastatic breast cancer. Oncology reports 2009; 21: 827-832 
8. Cady B, Nathan NR, Michaelson JS, Golshan M, Smith BL. Matched pair analyses of stage IV breast cancer with or without resection of primary breast site. Ann Surg Oncol 2008 Dec; 15(12):3384-95

9. Leung AM, Vu HN, Nguyen KA, Thacker LR, Bear HD. Effects of surgical excision on survival of patients with stage IV breast cancer. J surg Res. J Surg Res. 2010 Jun 1;161(1):83-8

10. Bafford AC, Burstein HJ, Barkley CR, Smith BL, Lipsitz S, Iglehart JD, Winer EP, Golshan M. Breast surgery in stage IV breast cancer: impact of staging and patient selection on overall survival. Breast cancer Res Treat 2009; 115:7-12

11. Ruiterkamp J., Ernst MF, Van de Poll-Franse LV, Bosscha, K, Tjan-Heijnen VCG, Voogd AC. Surgical resection of the primay tumour associated with improved survival in patients with distant metastatic breast cancer at diagnosis. EJSO 2009; 35:1146-1151

12. Neuman HB, Morrogh M, Gonen M, Van Zee KJ, Morrow M, King TA. Stage IV breast cancer in the era of targeted therapy. Cancer. 2010 Mar ;116(5):1226-33

13. Singletary SE, Allred C, Ashley P, Bassett LW, Berry D, Bland KI, Borgen PI, Clark G, Edge SB, Hayes DF, Hughes LL, Hutter RV, Morrow M, Page DL, Recht A, Theriault RL, Thor A, Weaver DL, Wieand HS, Greene FL. Revision of the American Joint Committee on Cancer staging system for breast cancer. J Clin Oncol. 2002 Sep 1;20(17):3628-36.

14. Brenton JD, Carey LA, Ahmed AA, Caldas C. Molecular classification and molecular forecasting of breast cancer: ready for clinical application? J Clin Oncol. 2005 Oct 10;23(29):7350-60

15. Sorlie T, Perou CM, Tibshirani R, Aas T, Geisler S, Johnsen H, Hastie T, Eisen MB, van de Rijn M, Jeffrey SS, Thorsen T, Quist H, Matese JC, Brown PO, Botstein D, Lonning PE, Borresen-Dale AL. Gene expression patterns of breast carcinomas distinguish tumor subclasses with clinical implications. Proc Natl Acad Sci U S A. 2001 Sep 11;98(19):10869-74

16. Guiu S, Michiels S, André F, Cortes J, Denkert C, , Hennessy BT, Sorlie T, Sotiriou C, Turner N, Van de Vijver M, Viale G, Loi S, Reis-Filho JS. Molecular subclasses of breast cancer: how do we define them? Ann Oncol 2012 ;23(12):2997-3006 
17. Perou CM. Molecular stratification of triple-negative breast cancers. Oncologist. 2011;16(Suppl 1):61-70.

18. Ruiterkamp J, Voogd AC, Booscha K, Tjan-Heijnen VCG, Ernst MF. Impact of breast surgery on survival in patients with distant metastases at initial presentation: a systematic review of the literature. EJSO 2009;35:1146-1151

19. Sant M, Allemani C, Berrino F. Breast carcinoma survival in Europe and United States. Cancer 2004 Feb 15;100(4):715-22

20. Voduc KD, Cheang MCU, Tysdesley S, Gelmon K, Nielsen TO, Kennecke H. Breast cancer subtypes and the risk of local and regional relapse. J Clin Oncol. 2010 Apr 1;28(10):1684-91

21. Nguyen PL, Taghian AG, Katz MS, Niemierko A, Abi Raad RF, Boon WL, Bellon JR, Wrong JS, Smith BL, Harris JR. Breast cancer subtype approximated by estrogen receptor, progesterone receptor, and her-2 is associated with local and distant recurrence after breast conserving therapy. J Clin Oncol 2008;26:2373-2378

22. Rebecca D, Trudeau M, Pritchard KI, Hanna WM, Khan HK, Sawka CA, Lickley LA, Sun P, Narod SA. Triple-negative breast cancer : clinical features and patterns of recurrence. Clin Cancer Res 2007;13:4429-4434

23. Warschkow R, Güller U, Tarantino I, Cerny T, Schmied BM, Thuerlimann B, et al. Improved Survival After Primary Tumor Surgery in Metastatic Breast Cancer: A Propensity-adjusted, Population-based SEER Trend Analysis. Ann Surg. 2016;263(6):1188-98.

24. Di Libero L, Varricchio A, Iannace C, Lo Conte D, Tartaglia E, Candela G, et al. Is primary surgery for locally advanced/metastatic breast cancer a better choice than chemotherapic treatment? Ann Ital Chir. 2014 Aug;85(4):317-22.

25. Lang JE, Tereffe W, Mitchell MP, Rao R, Feng L, Meric-Bernstam F, et al. Primary tumor extirpation in breast cancer patients who present with stage IV disease is associated with improved survival. Ann Surg Oncol. 2013 Jun;20(6):1893-9.

26. Harris E, Barry M, Kell MR. Meta-analysis to determine if surgical resection of the primary tumour in the setting of stage IV breast cancer impacts on survival. Ann Surg Oncol. 2013 Sep;20(9):2828-34. 
27. Hazard HW, Gorla sr, Sclotens D, Kiel Krystyna K, Gradishar WJ, Khan SA, Surgical resection of the primary tumor, chest wall control, and survival in women with metastatic brast cancer. Cancer 2008; 113(8):2011-19

28. Pedez-Fidalgo JA, Pimentel P, Caballero A, Bermejo B, Barrera JA, Burgues O, Martinez-Ruiz F, Chirivella I, Bosch A, Martinez-Agullo A, Lluch A. Removal of primary tumor improves survival in metastatic brast cancer. Does timing of surgery influence outcomes? The breast 2011; 20: 548-554

29. Rashaan ZM, Bastiaannet E, Portielje JEA, Van de Wter W, Van der Velde S, Ernst MF, Van de Velde CJH, Liefers GJ. Surgery in metastatic breast cancer: patients with a favorable profile seem to have the most benefit from surgery. EJSO 2012; 38: 52-56

30. Bernard-Marty C, Cardoso F, Piccart MJ. Facts and controversies in systemic treatment of metastatic breast cancer. The oncologist 2004; 9:617-632

31. Tosello G, Torloni MR, Mota BS, Neeman T, Riera R. Breast surgery for metastatic breast cancer. Cochrane Database Syst Rev. 2018 Mar 15;3:CD011276. doi: 10.1002/14651858.CD011276.pub2. Review.

\section{Figure legends}

Figure 1: Kaplan-Meier survival curves of all patients comparing surgery to no surgery

Figure 2: Overall survival according to breast cancer phenotype

Figure 3: Kaplan-Meier survival curves of all patients comparing surgery to no surgery

Figure 4: Survival and metastatic site number in the surgery group 


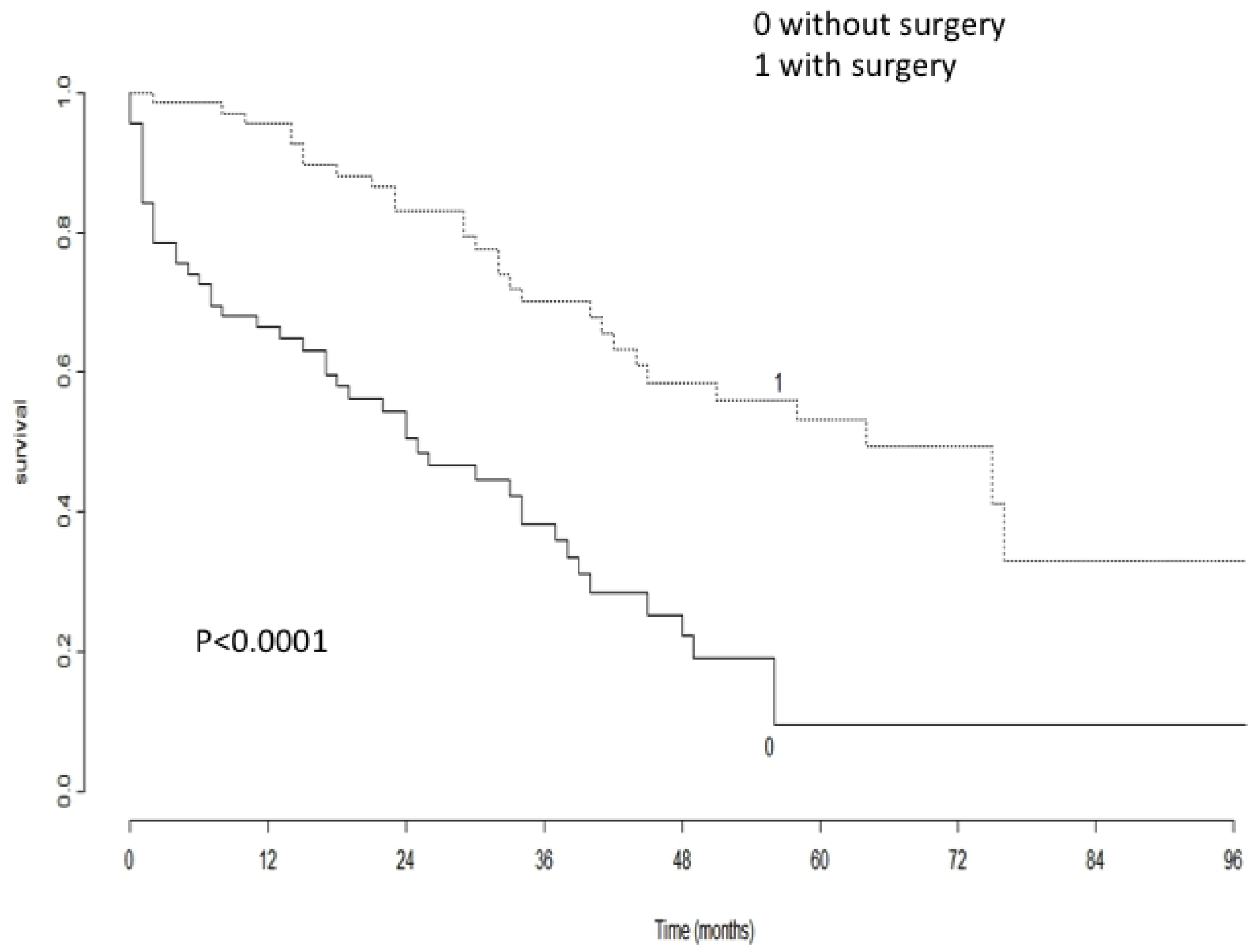




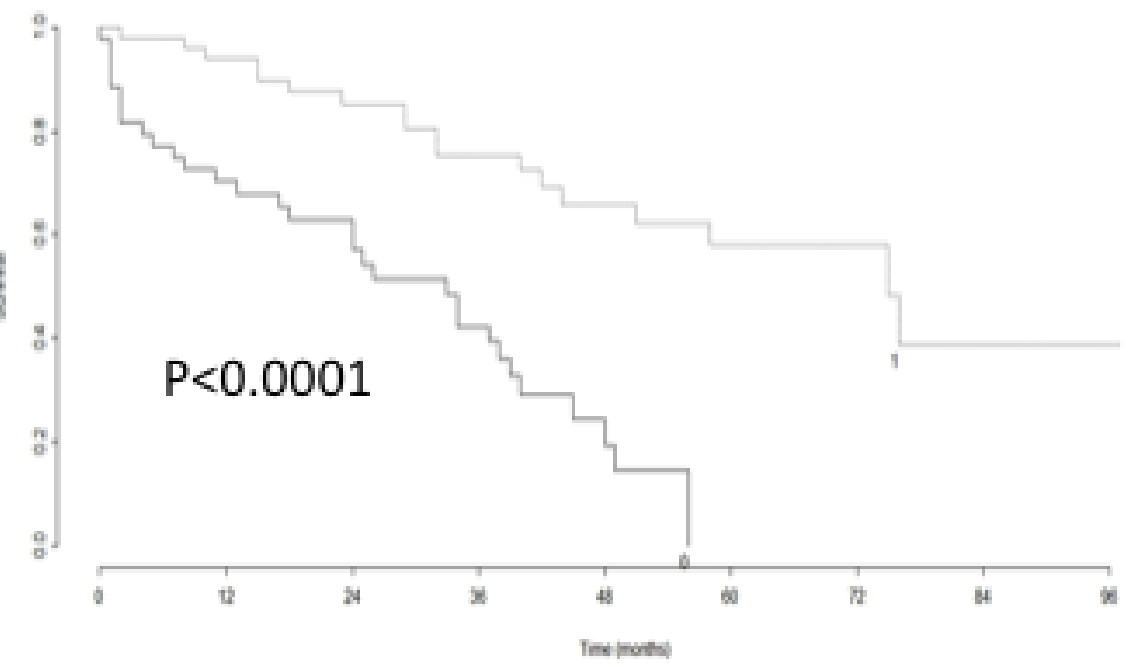

Luminal A

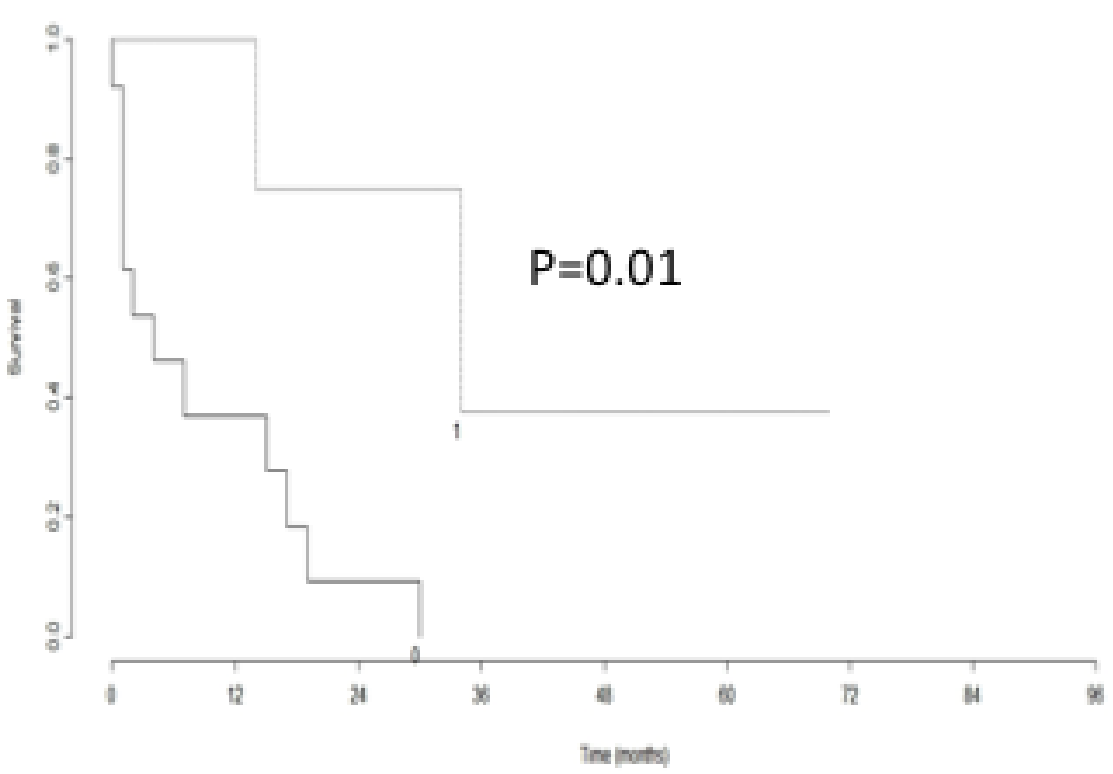

Triple negative

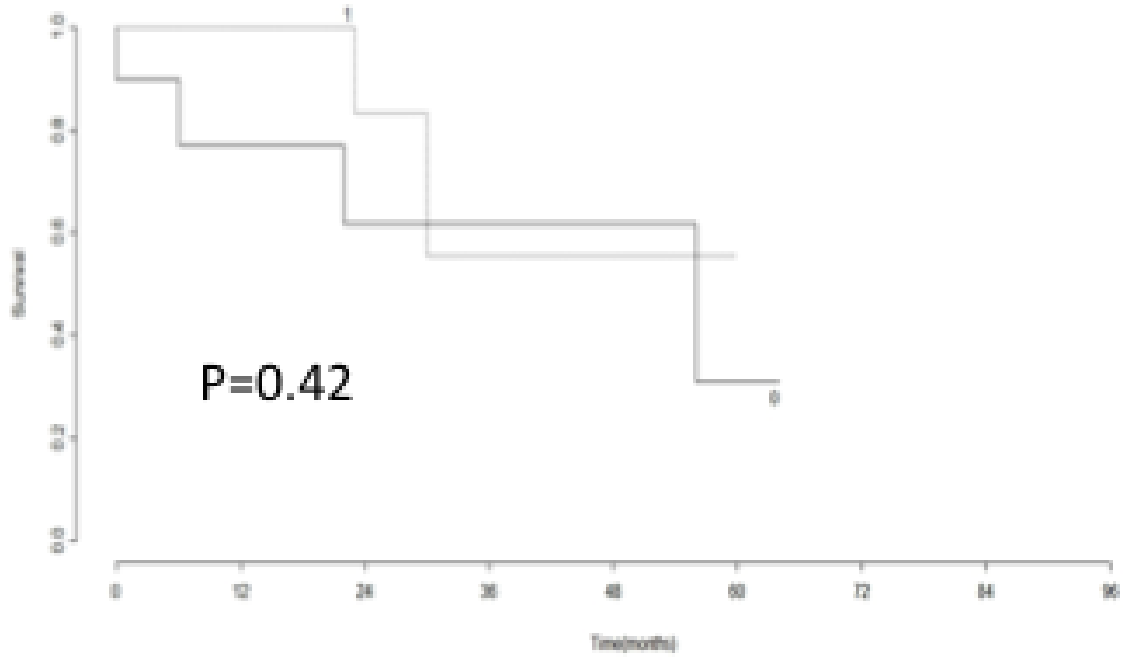

Luminal B

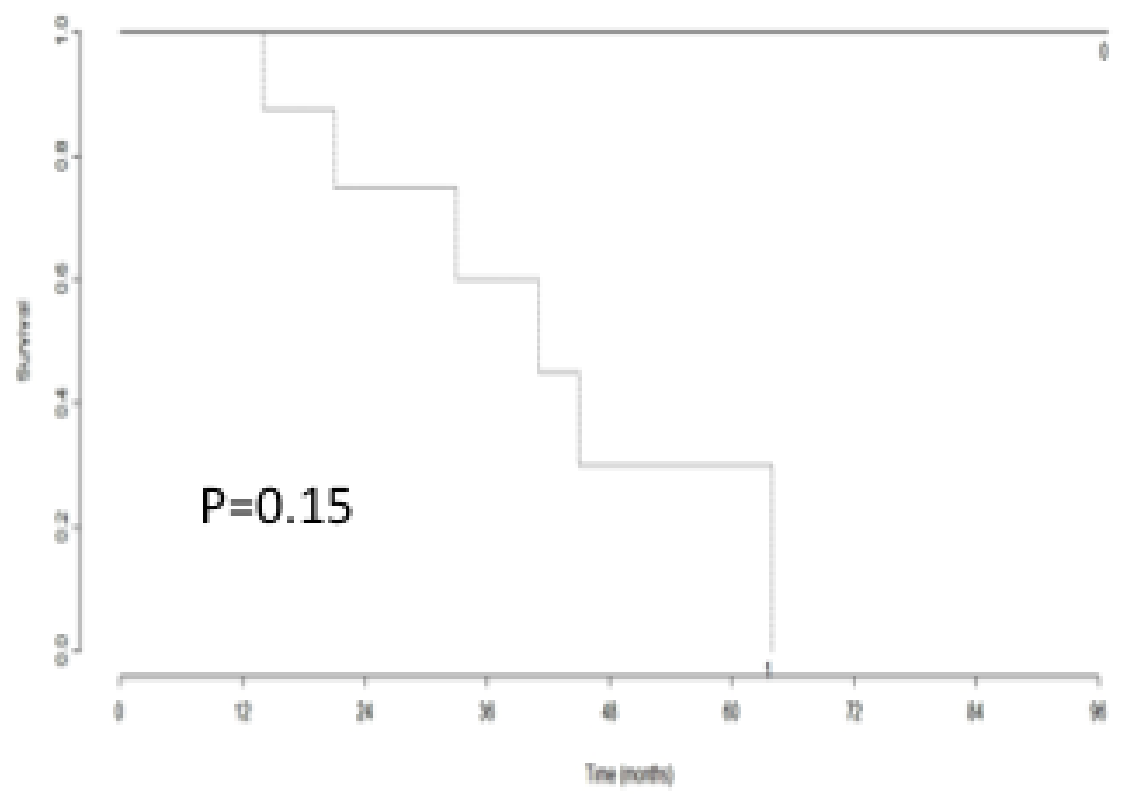

HER2 


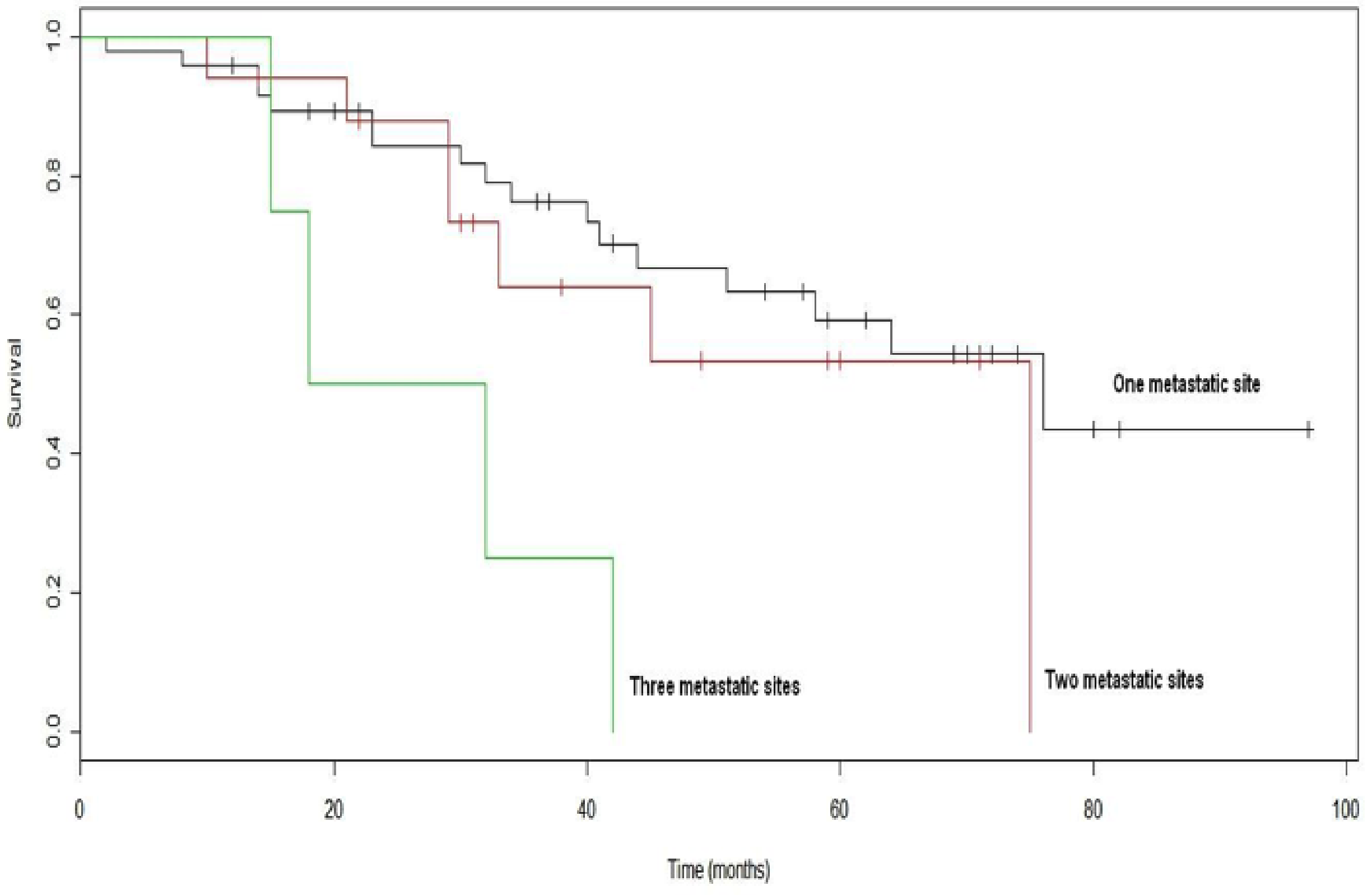

